\title{
Hannah Arendt e o nascimento dos conselhos ${ }^{1}$
}

\author{
Hannah Arendt and the birth of councils
}

\author{
José João Neves Barbosa Vicente \\ https://orcid.org/0000-0001-6823-3933 - E-mail: josebvicente@bol.com.br
}

\begin{abstract}
RESUMO
Em sua teoria política, especialmente em sua obra Da revolução, Hannah Arendt não apenas analisou e discutiu o sentido e o significado das revoluções (especialmente a Francesa e a Americana) e criticou o funcionamento da democracia representativa baseada no sistema de partidos políticos, mas também destacou os conselhos como espaços propícios onde os homens possam agir por meio de ação e do discurso, na presença de seus pares e se ocuparem juntos da vida política de seu país. Neste artigo, o objetivo principal é analisar o nascimento desses conselhos à luz da teoria política de Hannah Arendt, como verdadeiros espaços de liberdade que sempre surgiram no curso das grandes revoluções de forma espontânea e fora do âmbito dos partidos políticos ou de qualquer líder e que podem proporcionar aos cidadãos condições para uma efetiva participação política.
\end{abstract}

Palavras-chave: Ação. Conselhos. Hannah Arendt. Política. Revolução.

\begin{abstract}
In her political theory, especially in her work On Revolution, Hannah Arendt not only analyzed and discussed the sense and meaning of revolutions (especially French and American) and criticized the functioning of representative democracy based on the system of political parties,

\footnotetext{
1 O conteúdo deste artigo é parte da pesquisa realizada pelo autor no curso de pós-graduação na UFBA, sob a orientação do professor Dr. Genildo Ferreira da Silva.
} 
but also highlighted councils as propitious spaces where men can act through action and discourse, in the presence of their peers and to occupy together the political life of their country. In this article, the main objective is to analyze the birth of these councils in the light of Hannah Arendt's political theory, as true spaces of freedom that have always emerged in the course of great revolutions spontaneously and outside the scope of political parties or any leader and that can provide citizens with conditions for effective political participation.

Keywords: Action. Councils. Hannah Arendt. Politics. Revolution.

Em sua obra Da revolução (1988), Hannah Arendt realiza um estudo sistemático sobre o sentido e o significado das revoluções, especialmente a Americana e a Francesa, como acontecimentos que proporcionam o nascimento de uma nova realidade, isto é, de uma nova forma de governo com foco na liberdade e dirige duras críticas à democracia representativa baseada no sistema de partidos políticos que, para ela, proporciona aos cidadãos espaços reduzidos para uma efetiva participação política (VICENTE, 2019; 2020; 2020a; 2020b). Os conselhos, de um modo geral, são vistos e pensados por Hannah Arendt, como verdadeiros espaços de liberdade e como alternativas para superar os reduzidos espaços de ação política constatados por ela na democracia representativa baseada no sistema de partidos políticos. O objetivo deste artigo, no entanto, não consiste necessariamente em discutir o sentido e o significado das revoluções ou fazer uma análise ou um estudo sobre a relação entre o sistema de conselhos e a democracia representativa na teoria política de Hannah Arendt, mas sim refletir sobre o nascimento dos conselhos à luz dessa teoria, no intuito de destacá-los como verdadeiros espaços de liberdade, capazes de proporcionar a cada cidadão condições efetivas para uma participação política ativa e concreta.

Para que se alcance o sentido e o significado dos conselhos em Hannah Arendt, eles precisam ser entendidos não como mera especulação teórica ou imaginação da autora, mas sim como exemplos concretos que cumpriram funções eminentemente políticas, com registros no curso das grandes revoluções; é assim que eles são analisados e discutidos na teoria política de Hannah Arendt. Os conselhos surgiram no curso das grandes revoluções e sempre de modo espontâneo e fora do âmbito dos partidos políticos e sem interferência ou influência de qualquer tipo de líder. O primeiro exemplo desses conselhos, de acordo com os estudos de Hannah Arendt, foi uma espécie de "autogoverno" do povo francês que surgiu durante a revolução. Para a autora, não há dúvida de que as seções da Comuna de Paris e as sociedades populares que se espalharam por toda a França durante a revolução eram poderosos grupos de pressão dos pobres, a 'broca de diamante' da necessidade premente 'a que nada podia resistir',', mas nelas estavam também presentes de modo consistentes, "os germes, as primeiras frágeis manifestações de um novo tipo de organização política, de um sistema que faria com que as pessoas fossem 'participantes do governo, como queria Jefferson'"' (ARENDT, 1988, p. 195). O povo aprendia nessas seções "sua primeira lição sobre a 'noção e o gosto da liberdade"' (ARENDT, 1988, p. 196). E isso era possível porque essas seções nada mais eram do que um esforço organizacional espontâneo desse povo.

Nessas seções o povo exercia o debate e a troca de opiniões, independentemente se isso refletisse ou não sobre aqueles que estavam no poder. Hannah Arendt observa que foi a partir dessas seções que surgiu "o grande conselho municipal da Comuna de Paris" disseminado por toda a França, sob a forma de "sociedades revolucionárias". Ainda de acordo com a autora, 
essas experiências políticas ou "primeiros órgãos de uma república que nunca veio a existir", tiveram um triste fim, isto é, foram totalmente "esmagados pelos governos central e centralizados", por terem sido entendidos e considerados por eles, não apenas como simples "ameaça", mas também como "competidores do poder público" (ARENDT, 1988, p. 197). A aniquilação dessas seções por parte dos governos aconteceu por meio de métodos relativamente simples: eles se infiltraram nas sociedades populares e passaram a controla-las. A partir daí, como observou Hannah Arendt, eles proclamaram simplesmente que apenas a "facção parlamentar" dos jacobinos era verdadeiramente revolucionária e que, portanto, as sociedades populares eram todas "sociedades bastardas" e indignas de confiança. Esses mesmos métodos foram também utilizados no decorrer da Revolução Russa, quando "o partido bolchevista esvaziou e desvirtuou o sistema soviético revolucionário" (ARENDT, 1988, p. 198). Portanto, "um aparato de poder impiedosamente centralizado" e com justificativas de que representava "a soberania da nação", se encarregava de destituir o povo de seu poder, perseguindo "todos aqueles débeis e espontâneos órgãos de poder nascidos da revolução" (ARENDT, 1988, p. 195). Os governos, portanto, não se mostraram favoráveis aos conselhos em nenhum momento.

Em termos arendtianos, o esmagamento das seções não mostrou apenas a hostilidade dos governos em relação ao sistema de conselhos, mas também seus posicionamentos favoráveis ao desenvolvimento do sistema de partidos que se tornou tão comum que, hoje, quando se pensa a política, não se pensa em termos de conselhos, mas sim "em termos de política partidária", apesar das suas "deficiências - corrupção, incompetência e um incrível esbanjamento", bem como sua estrutura "oligárquica e até mesmo autocrática", claramente inapropriada "para todos os objetivos políticos" (ARENDT, 1988, p. 219). Conforme observação de Duarte, "esta forma de organização da coisa pública surgiu em contraste com as alternativas revolucionárias que contemplavam a participação popular ativa" (DUARTE, 2002, p. 76). Apesar de esmagados pelos governos, Hannah Arendt observa que as seções, bem como o plano de Jefferson sobre "repúblicas elementares", não deixaram de prenunciar "com uma precisão fantástica, aqueles conselhos [...] que haveriam de aparecer em todas as genuínas revoluções, ao longo dos séculos XIX e XX" (ARENDT, 1988, p. 199). E é importante destacar que, de acordo com a autora, sempre que eles apareceram no curso dessas revoluções, os conselhos jamais surgiram no âmbito dos partidos políticos ou influenciados por qualquer líder ou representante do povo.

Os partidos, como observou Hannah Arendt, jamais levantaram "a palavra de ordem dos conselhos"; ela "sempre brotou de rebeliões espontâneas". E os "ideólogos" pertencentes aos vários movimentos", cuja pretensão era "usar a revolução" para "impor ao povo uma forma preconcebida de governo", também não compreenderam adequadamente os conselhos em si mesmos e nem os receberam da melhor forma possível (ARENDT, 2009, p. 228-229). No contexto da teoria política de Hannah Arendt, o nascimento dos conselhos representa, na verdade, a contestação do sistema partidário em todas as suas formas, afinal, os "programas" dos partidos, independentemente da forma como eram elaborados, não deixavam de ser"sempre 'receitas adrede preparadas', que requeriam execução e não ação - 'para serem colocadas rigorosamente em prática"'. Os conselhos, por sua vez, sempre invocavam "a capacidade do cidadão comum de atuar e de formar sua própria opinião" (ARENDT, 1988, p. 210-211). Portanto, em termos de teoria política arendtiana, o sistema de partidos e o sistema de conselhos não são coisas idênticas, apesar de serem praticamente "contemporâneos", uma vez que não se conhecia nenhum deles "antes das revoluções e ambos são consequência do dogma moderno e revolucionário segundo o qual todos os habitantes de um determinado território têm o direito de acesso à esfera pública e política". No entanto, é preciso sublinhar que, para Hannah Arendt, os conselhos "sempre surgiram no curso da própria revolução, e brotaram do seio do povo 
como órgão espontâneos de ação e de ordenamento"; os partidos, por outro lado, jamais "surgiram durante uma revolução; ou eles a precedem, como no século XX, ou se desenvolvem a partir da extensão do sufrágio popular" (ARENDT, 1988, p. 216). Portanto, de um modo geral, os conselhos e os partidos não se distinguem apenas na estrutura e na forma como funcionam, mas também no modo como nascem ou surgem.

Os conselhos, de acordo com Hannah Arendt, sempre surgiram como organismos espontâneos de ação e ordenamento do povo em todas as verdadeiras revoluções que aconteceram ao redor do mundo. $E$ todas as vezes que eles surgiram, foram sempre de modo absolutamente inesperado e sem qualquer imitação consciente. Entre os historiadores, no entanto, observa a autora, existem "semelhanças bastante óbvias" entre esses conselhos que surgiram no curso das revoluções "e os municípios medievais, os cantões suíços, entre os 'agitadores' ingleses do século XVIII - ou antes 'ajustadores', como eram originalmente chamados - e o Conselho Geral do exército de Cromwell", mas para Hannah Arendt, é preciso destacar "o ponto essencial", a saber, nenhum desses exemplos citados "teve a menor influência sobre as mentes das pessoas que, no curso de uma revolução, se organizaram espontaneamente em conselhos" (ARENDT, 1988, p. 209-210). Portanto, em termos arendtianos, "não se pode creditar a nenhuma tradição, seja revolucionária, seja pré-revolucionária, o surgimento e ressurgimento regular do sistema de conselhos" (ARENDT, 1988, p. 209). Ainda de acordo com a teoria política de Hannah Arendt, os conselhos jamais se realizaram efetivamente como uma "nova forma de governo" por um período de tempo significativo em nenhum país do mundo. Eles sempre nasceram e pereceram "em todo lugar e em toda época", principalmente porque foram atacados e destruídos "pela burocracia dos estados-nações ou pelas máquinas dos partidos", mas eles sempre parecem "corresponder e brotar da própria experiência da ação política" (ARENDT, 1973, p. 199). Em todas as verdadeiras revoluções, os conselhos, de acordo com Hannah Arendt, sempre nasceram de forma completamente espontânea. Ainda de acordo com a autora, apesar de terem surgidos em todas essas revoluções, os conselhos são todos fenômenos surpreendentes e não existe neles qualquer rastro de "continuidade" e nem de "influência organizada"; os conselhos jamais surgiram "como resultado de uma tradição ou teoria revolucionária consciente" (ARENDT, 1973, p. 199). Portanto, enxergar o nascimento dos conselhos sem levar em conta essas características, significa certamente para Hannah Arendt, abrir mão de captar o significado e o sentido desses verdadeiros espaços de liberdade.

Os conselhos, em termos arendtianos, nasceram todos "exclusivamente com as ações e demandas espontâneas do povo", jamais nasceram a partir de deduções ideológicas e nem foram "previstos e muito menos pré-concebidos por qualquer teoria sobre a melhor forma de governo" (ARENDT, 1958, p. 30). Conforme observações de Machado, os conselhos se apresentam para Hannah Arendt "tal qual a ação"; ou seja, "como o início de algo inédito" que interrompe "o curso da história de forma como 'se nunca tivesse havido nada semelhante antes"' (MACHADO, 2013, p. 162). Hannah Arendt pensa o "conceito" de conselhos, como sublinhou Winfield (1988, p. 280), livre, por exemplo, das "limitações marxistas e sindicalistas", para ela, os conselhos são órgãos espontâneos de ação política abertos a todos aqueles que desejam participar, independentemente do seu lugar na sociedade. Assim, como disse Avritzer (2006, p. 162), apesar de Hannah Arendt ter resgatado "uma discussão que pertence à tradição marxiana", sua interpretação, no entanto, é radicalmente distinta dessa tradição, pois ela nega "qualquer elemento partidário no entendimento dos conselhos". Nesse sentido, ainda de acordo com Avritzer, a interpretação arendtiana dos conselhos não apresenta apenas uma alternativa "ao problema da representação", ela apresenta também uma alternativa "à concepção marxiana de conselhos operários". A interpretação de Hannah Arendt do sistema de conselhos é, em essência, como disse Fry (2009, 
p. 63), uma alternativa ao modo de pensar totalitário "que desencoraja a participação das pessoas" nos debates políticos através "do uso do terror". Os conselhos proporcionam a cada cidadão espaços adequados para debates e participação política ativa e efetiva.

Como órgãos espontâneos de ação e de ordenamento do povo que sempre nasceram no curso da própria revolução, os conselhos são vistos por Hannah Arendt, como um sistema que "contradiz" de modo claro e flagrante, "o teórico 'modelo de revolução do século XX - planejada, preparada e executada, quase que com fria precisão cientifica, pelos revolucionários profissionais"' (ARENDT, 1988, p. 209-210). O sistema de conselhos também, ainda de acordo com Hannah Arendt, "contradiz mais veementemente o velho adágio acerca das 'naturais' inclinações anarquistas e desordeiras de um povo que se vê livre do seu governo", principalmente porque sempre que surgiu no curso das grandes revoluções e brotando "do seio do povo", sempre se preocupou "com a reorganização da vida política e econômica do país e com o estabelecimento de uma nova ordem" (ARENDT, 1988, p. 216). Como órgãos decorrentes tão somente dos impulsos organizacionais do próprio povo, os conselhos representam, sem dúvida, para Hannah Arendt, não apenas espaços autênticos de liberdade política onde os cidadãos podiam ver e serem vistos em ação na presença de seus pares, isto é, podiam agir em conjunto e desfrutar da "felicidade pública", mas também como momentos "raros e decisivos" na história da humanidade que, certamente, provam que a tendência do povo na ausência de um poder estabelecido, não é necessariamente a desorganização ou a desordem, mas sim a auto-organização.

De um modo geral, para Hannah Arendt, os conselhos significam um "novo começo" que se constitui como verdadeiro espaço de ação política destinado a todos os cidadãos, no qual cada um deles possa desfrutar do princípio que inspirou as grandes revoluções. Como espaços de liberdade, os conselhos oferecem a cada cidadão a oportunidade de participar efetivamente das questões políticas, isto é, de fazer ouvir a sua voz, exercer sua liberdade através de debates e trocas de opiniões na presença de seus pares e se sentir um participante permanente e efetivo dos "negócios do governo", não um participante "atuante politicamente" apenas nos dias de eleição dentro de uma cabine de votação onde só tem lugar para um, e onde a política se transforma em "uma atividade de reflexão interiorizada". Hannah Arendt se mostra tão entusiasmada com o sistema dos conselhos e reconhece que, de fato, pormenorizar todas as suas "potencialidades" é uma tentação que se corre, mas para ela, o correto mesmo não é insistir em pormenorizá-los, mas sim concordar com Jefferson e "iniciá-los, nem que seja apenas com um único propósito, e logo se tornará evidente para que outros objetivos serão também os melhores instrumentos" (ARENDT, 1988, p. 223); afinal, as palavras de ordem nos conselhos são sempre as seguintes: "queremos participar, queremos debater, queremos que nossas vozes sejam ouvidas em público, e queremos ter uma possibilidade de determinar o curso político de nosso país" (ARENDT, 1973, p. 200). Como uma espécie de pequenos "espaços públicos" dentro de um mesmo país, os conselhos facilitam a organização e a reunião dos cidadãos em torno das questões políticas que dizem respeito a todos.

Nos conselhos, ninguém é menor ou maior do que o outro e nem se obedece a um “líder supremo" e pré-definido. De acordo com observações de Que, nos conselhos como descritos por Hannah Arendt, todos os cidadãos "discutem, debatem e decidem sobre os assuntos públicos" em condições iguais; ninguém tem mais liberdade do que o outro por ser "mais inteligente", ter "melhores ideias", pertencer a uma "família distinta" ou possuir "mais propriedades". Todas as ideias e opiniões apresentadas ao "corpo dos pares" são apreciadas "sem qualquer distinção pré-definida" (QUE, 1997, p. 167). Isso porque a oportunidade de expressar suas opiniões e de participar nos assuntos públicos deve ser dada a todos, esta é, certamente, a base 
sobre a qual encontra-se alicerçada a ideia arendtiana de sistema de conselhos. É como se todos nós estivéssemos reunidos e sentados ao redor de uma grande mesa para conversarmos e discutirmos as nossas ideias e opiniões, com o objetivo de chegarmos a uma decisão racional como grupo. Afinal, como disse Hannah Arendt, se a mais importante "finalidade" de todas as grandes revoluções "era a liberdade e a constituição de um espaço público onde a liberdade pudesse aparecer", em tal caso, "as republicas elementares dos distritos, o único espaço tangível onde todos podiam ser livres, eram efetivamente a finalidade da grande república"; o sistema distrital tinha, de um modo geral, um pressuposto básico, independentemente se Jefferson tinha ou não consciência disso, esse pressuposto se resume basicamente em três frases fundamentais, a primeira, "ninguém podia ser chamado feliz, se não partilhasse da felicidade pública"; a segunda, "ninguém podia ser chamado livre, se não tivesse experimentado a liberdade pública" e a terceira, "ninguém podia ser chamado livre ou feliz sem participar, e ter uma parte, no poder público" (ARENDT, 1988, p. 203-204). Infelizmente, apesar de todas essas qualidades e preocupação com a participação política efetiva do povo, os conselhos não tiveram a chance de se firmarem efetivamente por um longo período de tempo.

Os conselhos que nasceram ao longo do curso das grandes revoluções, diz Hannah Arendt, "sempre foram, sem dúvida, democráticos, mas em um sentido nunca visto antes e nem pensado"; no entanto, infelizmente, todos eles praticamente caíram no esquecimento e nunca se desenvolveram efetivamente a ponto de se tornarem de fato, uma nova forma de governo capaz de proporcionar aquele tipo de participação ativa na política que se mostrou ao longo das revoluções (ARENDT,1958, p. 30). Essa queda no esquecimento ao longo do tempo de todos os conselhos que nasceram no curso das verdadeiras revoluções, não foi por acaso, ela aconteceu porque os conselhos nunca foram levados a sério. Como disse Hannah Arendt, "eles foram ignorados completamente pelos estadistas, historiadores, teóricos da política e, o que é mais significativo, pela própria tradição revolucionária" (ARENDT, 1988, p. 199). Os revolucionários profissionais, por exemplo, como observou Hannah Arendt em seus estudos, mesmo estando interessados em mudar o modo de vida da comunidade, não apoiaram os conselhos populares, preferiram defender ideias ligadas às formas antigas de poder e associação política por meio de facção; assim, ainda de acordo com as análises da autora, a "má-fé" e a "avidez de poder", não podem ser apontadas como "fatores decisivos que levaram os revolucionários profissionais a se voltarem contra os órgãos revolucionários do povo". De acordo com Hannah Arendt, a atitude desses "revolucionários" estão muito mais ligadas às "convicções básicas que os partidos revolucionários partilhavam com todos os outros partidos. Eles concordavam em que o objetivo do governo era o bem-estar do povo, e que a essência da política não era ação, mas administração (ARENDT, 1988, p. 218). O que se percebe, portanto, é que apesar de terem se constituídos como espaços reais de liberdade e participação política efetiva do povo, os conselhos não se efetivaram como uma nova forma de governo, porque não tiveram a atenção e o apoio necessários.

Hannah Arendt destaca em seus escritos que nem mesmo aqueles historiadores simpatizantes da revolução ou que se colocavam claramente do lado dela "e que não podiam deixar de mencionar o surgimento dos conselhos em seus populares em seus relatos", se preocuparam efetivamente em alcançar o verdadeiro sentido e significado desses acontecimentos; eles simplesmente consideraram os conselhos "como nada mais do que órgãos essencialmente temporários, na luta revolucionária pela libertação". Ainda de acordo com Hannah Arendt, essa atitude significa essencialmente que esses historiadores não foram capazes de perceber, de fato, "até que ponto o sistema de conselho os confrontava com uma nova forma de governo inteiramente nova, com um novo espaço para liberdade, constituído e organizado no próprio curso da revolução" (ARENDT, 1988, p. 199). Também faltou perceber que os conselhos nada tinham a 
ver, por exemplo, com os programas partidários predeterminados. É importante destacar que, nessas observações de Hannah Arendt, pelo menos dois nomes devem ser considerados como exceções, a saber, Marx e Lenin. De acordo com a autora, eles reconheceram e saudaram o surgimento dos conselhos e ficaram impressionados ao "testemunharem seu espontâneo aparecimento, o primeiro durante a Comuna de Paris de 1871, e o último em 1905, durante a primeira Revolução Russa" (ARENDT, 1988, p. 204). Eles sabiam que o nascimento dos conselhos ao longo do curso das revoluções não era algo capaz de ser explicado por "imitação consciente" e nem por uma "reminiscência do passado", afinal, em termos arendtianos, se tratava do nascimento de uma nova forma de governo.

Mas, de acordo com Hannah Arendt, devido ao despreparo tanto de Marx quanto de Lenin para lidar com tais acontecimentos e também porque se viram diante de uma repetição de um fenômeno novo, eles nunca sequer suspeitaram que esses conselhos "pudessem ser os germes de uma nova forma de governo", para ambos, os conselhos se tratavam de "meros instrumentos que deviam ser postos de lado quando a revolução chegasse ao seu término" (ARENDT, 1988, p. 205). Percebe-se, portanto, que entre os pensadores, historiadores e revolucionários, Marx e Lenin são singularizados por Hannah Arendt porque reconheceram os conseIhos como uma forma política contrária às suas concepções, mas infelizmente tal reconhecimento não serviu para fortalecer os conselhos como a "única forma inédita de governo que despontou da revolução", porque foram incapazes de adaptar seus pensamentos e ações ao novo. Nas palavras de Hannah Arendt, eles se depararam com duas alternativas: "ajustar suas ideias e ações ao que havia de novo e inesperado, ou ir ao extremo da tirania e da repressão". Conforme observação da autora, diante dessas duas alternativas, optaram pela segunda; isso mostra o medo que os homens, "mesmos os mais radicais e menos convencionais, têm de coisas nunca dantes vistas, de pensamentos nunca dantes cogitados, de instituições nunca dantes experimentadas" (ARENDT, 1988, p. 206). E os conselhos eram algo novo sem qualquer exemplo ou modelo ao longo da história da humanidade.

O sistema de conselhos que nasceram ao longo das verdadeiras revoluções, não são e nem devem ser entendidos como organismos políticos transitórios ou como "órgãos temporários da revolução". De acordo com a teoria política de Hannah Arendt, para que seja possível entender e compreender seu sentido e significado, os conselhos precisam ser considerados como verdadeiros "espaços de liberdade" que nasceram sempre de forma espontânea e por meio dos "impulsos organizacionais do próprio povo"; portanto, fora do âmbito dos partidos políticos e sem qualquer influência ou interferência de um líder ou um representante. $E$ todas as vezes que surgiram ao longo das revoluções, os conselhos sempre renovaram a vontade do povo pela ação política ativa e resgataram a dignidade da política; sempre se constituíram como espaços de liberdade onde todos eram iguais e podiam debater e trocar opiniões sobre questões políticas na presença de seus semelhantes. Os conselhos, conforme observação de Hannah Arendt, jamais traçaram como objetivo criar um "paraíso na terra", uma "sociedade sem classes" ou um "sonho de fraternidade socialista ou comunista"; o objetivo dos conselhos sempre foi o de "lançar as bases de uma república que se firmasse em toda a sua plenitude" e que possibilitasse a todos os cidadãos a participação ativa nos assuntos políticos; ou em outras palavras, estabelecer a "verdadeira república". É por isso que, para Hannah Arendt, eles devem ser levados a sério, porque representam o verdadeiro espírito da revolução, isto é, a paixão pela "liberdade pública" ou "felicidade pública"; os conselhos são, na verdade, a única instituição inteiramente nova e espontânea da história revolucionária. Os conselhos ensinam "que 'a boa organização não precede a ação, mas é seu produto" (ARENDT, 2008, p. 62). Levar os conselhos a sério e valorizar sua função significa certamente, em termos arendtianos, se colocar a favor 
dos espaços de liberdade onde todos têm a oportunidade de exercer uma participação política ativa e efetiva.

\section{Referências}

ARENDT, Hannah. A condição humana. Trad. Roberto Raposo. Rio de janeiro: Forense, 2009. ARENDT, Hannah. Crises da república. Trad. José Volkmann. São Paulo: Perspectiva, 1973. ARENDT, Hannah. Da revolução. Trad. Fernando Dídimo Vieira. Brasília: UnB, 1988.

ARENDT, Hannah. Homens em tempos sombrios. Trad. Denise Bottmann. São Paulo: Companhia das Letras, 2008.

ARENDT, Hannah. Totalitarian imperialism: reflections on the Hungarian Revolution. Journal of politics, v.20, $n^{\circ} 1$, p. 5-43, fev./1958.

AVRITZER, Leonardo. Ação, fundação e autoridade em Hannah Arendt. Lua Nova, São Paulo, n.68, p. 147-167, 2006.

DUARTE, André. Hannah Arendt e a modernidade: esquecimento e redescoberta da política. In: CORREIA, Adriano (Org.). Transpondo o abismo: Hannah Arendt entre a filosofia e a política. Rio de Janeiro: Forense Universitária, 2002.

FRY, Karin. Arendt: a guide for the perplexed. London: Continuum, 2009.

MACHADO, Felipe Daniel Amorim. Arendt e Schmitt: diálogos sobre a política. Belo Horizonte: Arraes Editores, 2013.

QUE, Nemesio. The structure of civil society: Hannah Arendt on revolution, freedom and the council system. In: MIAOYANG, Wang; XUANMENG, Yu and DY, Manuel (Eds.). Civil society in a chinese context. Washington DC: Council for Research in Values and Philosophy, 1997.

VICENTE, José João Neves Barbosa. Arendt e a democracia representativa: comentários introdutórios. Sapere Aude: Revista de Filosofia, v. 11, p. 70-81, 2020b.

VICENTE, José João Neves Barbosa. Considerações de Arendt sobre a Revolução Francesa: comentários introdutórios. Synesis, v. 11, p. 106-121, 2019.

VICENTE, José João Neves Barbosa. Hannah Arendt: considerações sobre a Revolução Americana. Argumentos: Revista de Filosofia (ONLINE), v. 12, p. 87-94, 2020.

VICENTE, José João Neves Barbosa. Hannah Arendt e a revolução: reflexões introdutórias. Revista Diaphonia, v. 6, p. 146-153, 2020a.

WINFIELD, Richard Dien. Reason and justice. Albany, NY: SUNY Press, 1988.

\section{Sobre o autor}

José João Neves Barbosa Vicente

Doutor em Filosofia. Professor Adjunto de Filosofia da Universidade Federal do Recôncavo da Bahia (UFRB). 